\title{
ANALISIS DESKRIPTIF KEKUATAN OTOT PERAS TANGAN
}

\author{
Reyhan Tino ${ }^{1}$, Hayati ${ }^{2}$, Shandy Pieter Pelamonia ${ }^{3}$ \\ email: $\underline{\text { reyhan.tino007@ gmail.com }}$, $\underline{\text { hayati@ unipasby.ac.id }}{ }^{2}, \underline{\text { shandypieter@unipasby.ac.id }^{3}}$ \\ $\mathbf{1 , 2 , 3}$ Universitas PGRI Adi Buana Surabaya
}

\begin{abstract}
Abstrak
Kekuatan maksimum dari otot peras tangan akan memberi kekuatan pada genggaman tangan saat melakukan pukulan. Dengan kekuatan otot peras tangan yang baik maka dapat meningkatkan kekuatan pukulan yang berpengaruh pada akurasi. Tujuan dari penelitian ini adalah untuk mengetahui pengaruh otot peras tangan terhadap pukulan pada permainan bulutangkis, dengan kekuatan otot peras tangan yang besar maka dapat meningkatkan kekuatan ayunan tangan yang dapat mempengaruhi hasil pukulan. Penelitian ini menggunakan pendekatan penelitian kuantitatif dengan jenis penelitian analisis deskriptif. Pendekatan penelitian ini adalah mengumpulkan data berupa angka. Metode yang digunakan adalah analisis deskriptif. Subjek penelitian adalah anggota unit kegiatan mahasiswa (ukm) bulutangkis Universitas PGRI Adi Buana Surabaya yang berjumlah 20 anggota. Metode pengumpulan data pada penelitian ini ntuk mengukur kekuatan otot peras tangan dengan menggunkan alat ukur handgrip dynamometer. Berdasarkan hasil analisis deskriptif menggunakan SPSS 20, menunjukkan bahwa rata-rata kekuatan otot peras tangan pada anggota laki-laki adalah 44,85 yang termasuk dalam kategori "sedang". Kemudian untuk kekuatan otot peras tangan anggota perempuan rata-rata adalah 27,20 yang termasuk dalam kategori "sedang". Dari hasil tersebut dapat diketahui kekuatan otot peras tangan pada anggota unit kegiatan mahasiswa (ukm) bulutangkis Universitas PGRI Adi Buana Surabaya berada dalam kategori "sedang".
\end{abstract}

Kata Kunci: Kekuatan otot peras tangan, Grip Strenght Test, Hand Dynamometer.

\section{Abstrack}

The maximum strength of the hand-squeeze muscles will give the grip strength when making the punch. With good hand-wringing muscle strength, it can increase the power of the punch which affects accuracy. The purpose of this study was to determine the effect of handsqueezing muscles on blows in badminton. With a large hand-squeeze muscle strength, it can increase the strength of the hand swing which can affect the outcome of the hit. This study uses a quantitative research approach with descriptive analysis research type. This research approach is to collect data in the form of numbers. The method used is descriptive analysis. The research subjects were members of the student activity unit (ukm) badminton at the PGRI Adi Buana University Surabaya, which amounted to 20 members. The data collection method in this study was to measure the strength of the hand-squeeze muscles using a dynamometer handgrip measuring instrument. Based on the results of descriptive analysis using SPSS 20, it shows that the average hand-squeeze muscle strength of male members is 44.85, which is included in the "medium" category. Then for the hand-squeezing muscle strength of the average woman is 27.20 which is included in the "medium" category. From these results, it can be seen that the strength of the hand-squeezing muscles in the badminton student activity unit (ukm) of the Universitas PGRI Adi Buana Surabaya is in the "medium" category.

Keywords: Hand squeeze muscle strength, Grip Strength Test, Hand Dynamometer. 


\section{A. Pendahuluan}

Saat ini, mulai dari anak-anak hingga orang dewasa, olahraga sudah menjadi gaya hidup masyarakat Indonesia. Setiap individu memiliki tujuan olahraga yang berbeda, beberapa tujuan hanya untuk memperkaya waktu luang, hiburan, kesehatan, kebugaran, prestise, atau untuk mencapai diri sendiri dan membuat bangga seluruh negeri. Saat pandemi Covid-19, kebutuhan untuk tetap sehat menjadi lebih penting.Selain itu, masyarakat cenderung lebih banyak melakukan aktivitas di luar ruangan seperti olahraga, bekerja, dan berbelanja kebutuhan pokok. Selain menjaga kesehatan, olahraga juga membantu menjaga sel-sel penuaan dalam tubuh dan memperkuat kekebalan tubuh untuk mencegah masuknya bakteri penyebab penyakit ke dalam tubuh.Jenis olahraga di tengah pandemi yang bisa dilakukan di dalam rumah di antaranya adalah berlari dengan treadmill, mengayuh sepeda statis, yoga, senam, push up, sit up, plank dan squat. Ketika bosan berolahraga di rumah dan ingin melakukan olahraga outdoor, Sebisa mungkin cari lokasi yang tidak terlalu ramai untuk berolahraga, mengurangi penggunaan alat olahraga secara bersama-sama, dan tetap menjaga protokol kesehatan. Menurut Dr. dr. Prasetyadi Mawardi (2020) dalam buku saku covid-19 Universitas Negeri Semarang, berolahraga selama kurang lebih 15 hingga 30 menit dengan terpapar oleh sinar matahari yang terdapat vitamin D yang bermanfaat untuk menjaga kesehatan sistem kekebalan tubuh, otak, dan syaraf. Disini terlihat bahwa kegiatan olahraga dapat meningkatkan fungsi organ serta kesegaran jasmani dan dapat menjaga imunitas tubuh. Dalam olahraga tersebut terdapat dua jenis olahraga yaitu; olahraga yang diperlombakan misalnya: renang, atletik dan olahraga yang dipertandingkan seperti: tinju, tenis, sepakbola, bulutangkis dan sebagainya. Contohnya seperti olahraga bulutangkis di Indonesia telah menempatkan diri sebagai olahraga yang sangat populer di kalangan masyarakat, maka dari itu olahraga ini juga memerlukan perhatian khusus, baik dalam usaha mencari bibit yang baru maupun dalam usaha meningkatkan prestasi atlet, khususnya dalam olahraga Bulu tangkis. Hampir semua lapisan masyarakat pernah memainkan permainan bulu tangkis yang dimulai dari pertandingan antar kelas sampai pertandingan antar sekolah kemudian pertandingan tingkat pedesaan seperti kejuaraan dalam memeriahkan hari ulang tahun kemerdekaan Republik Indonesia.

Proses pembinaan dalam olahraga tidak bisa langsung diselesaikan, melainkan harus melalui proses yang panjang. Untuk mencapai kinerja terbaik dibutuhkan ketekunan, pengorbanan, tekad, dan motivasi yang dilandasi hasil terbaik. Memulai pelatihan sejak usia dini adalah proses memperoleh prestasi terbesar. Karena saat masih muda bisa melakukan pembinaan dan latihan teknik dalam waktu yang lama, dan juga ajang mencari pemain bulutangkis berbakat. Seorang atlet bertalenta merupakan salah satu syarat mutlak untuk pencapaian perkembangan. Hal ini sesuai dengan pernyataan Noor Akhmad, A. M. (2016: 56) "Pembibitan adalah upaya yang diterapkan untuk menjaring atlet berbakat dalam olahraga prestasi yang diteliti secara terarah dan intensif melalui orang tua, guru, dan pelatih pada suatu cabang olahraga. Bertujuan untuk menyediakan calon atlet berbakat dalam berbagai cabang olahraga prestasi untuk kemudian dilanjutkan dengan pembinaan yang lebih intensif'. Bulutangkis merupakan olahraga yang menggunakan alat yang dinamakan raket dan kok atau shuttlecock, yang dimainkan oleh 2 atau 4 orang pemain. Cara memainkan olahraga ini adalah dengan memukulkan kok dengan menggunakan raket dengan target melewati jaring atau net yang terletak di tengah lapangan dengan tinggi tertentu bertujuan agar lawan tidak dapat mengembalikan shuttlecock dan jatuhnya shuttlecock harus berada di daerah lawan. Bulutangkis sama dengan cabang olahraga lainnya, dalam olah raga ini para atlit harus menguasai basic skill agar menjadi pemain bulutangkis yang unggul dan berprestasi. Dalam permainan bulu tangkis, terdapat keterampilan dasar pemain atas dan bawah. Menurut Syahri Alhusin (2007: 35), seorang atlet bulutangkis harus mampu menguasai teknik pukulan atas (overhead stroke) maupun pukulan bawah (underhand stroke). 
Teknik dasar bulutangkis Penguasaan teknik dalam bulu tangkis sangat penting karena teknik tersebut memudahkan kita untuk mendapatkan poin. Adapun keterampilan dasar olahraga bulutangkis dapat dibagi menjadi empat bagian yaitu pegangan raket (grip), pukulan pertama (service), pukulan melampaui kepala (overhead stroke), dan pukulan dengan ayunan bawah (underhand stroke). Mengenai hal ini, Subardjah (2000:21) menjelaskan: Keterampilan dasar atau teknik dasar permainan bulutangkis yang perlu dipelajari secara umum dapat dikelompokkan ke dalam beberapa bagian yaitu: 1) cara memegang raket (grips), 2) sikap berdiri (stance), 3) gerakan kaki (footwork), dan 4) pukulan (strokes).

Menurut M. Sajoto (2009), apabila seseorang ingin prestasi yang optimal, perlu memiliki empat hal yang meliputi (1) pengembangan fisik, (2) pengembangan teknik, (3) pengembangan mental, dan (4) kematangan juara. Adapun faktor-faktor penentu prestasi olahraga menurut meliputi (1) aspek biologis yang terdiri atas potensi atau kemampuan dasar tubuh, fungsi organ tubuh, struktur dan postur tubuh, gizi, (2) aspek psikologis yang terdiri atas intelektual, motivasi, kepribadian, koordinasi kerja otot dan syaraf, (3) aspek lingkungan, (4) aspek penunjang. Untuk menghasilkan pukulan yang baik dan benar tentu saja tidak lepas dengan latihan dan pembinaan dengan rancangan yang sudah terorganisir dengan baik. Yang termasuk faktor fisik diantaranya power lengan dan kekuatan tangan. Pada gerakan pukulan yang ada di permainan bulutangkis lebih banyak didominasi oleh gerakan otot lengan. Oleh karena itu, perlu koordinasi gerak yang baik dari gerakan seperti pada pukulan lob secara cepat diubah menjadi pukulan smash yang dapat dimanfaatkan untuk mengejutkan lawan. Dengan demikian, semakin cepat perubahan itu dilakukan maka semakin banyak pula komponen gerakan yang harus dikoordinasikan. Kekuatan menurut Bakoro, D.A. (2016) adalah kemampuan otot untuk dapat mengatasi tekanan atau beban dalam menjalankan aktifitas. Dalam menggenggam grip raket untuk memperkokoh pegangan yang kuat seorang atlet sudah tentu membutuhkan kekuatan tangan, genggaman raket pada permainan bulutangkis dapat diubah-ubah setiap saat tergantung pada jenis pukulan yang akan dilakukan. Agar faktor power lengan dan kekuatan tangan dapat berkembang optimal, seorang pebulutangkis perlu latihan rutin dengan memperhatikan pola latihan. Pemain bulutangkis harus menguasai teknik pukulan dan fisik untuk menerbangkan shuttlecock ke bidang lapangan lawan. Menurut Sudarsono.S. (2011) Adapun yang termasuk fisik adalah kekuatan genggaman saat memegang raket. Kekuatan otot peras tangan yang maksimal akan memberi kekuatan pegangan antara tangan dan saat melakukan pukulan.

Menurut, Kisner, C., \& Colby (2012) komponen performa dijabarkan menjadi tiga yaitu power, endurance (daya tahan), strength (kekuatan). Strength atau kekuatan otot diartikam sebagai kapasitas otot dalam menerima suatu beban yang diberikan. Menurut Setiowati (2014), kekuatan otot dipengaruhi oleh beberapa faktor antara lain usia, genetik, gender, latihan, suplemen, nutrisi, dan kesehatan khususnya muskuloskeletal. Secara gender dilaporkan bahwa laki-laki memiliki kekuatan yang lebih besar dibandingkan perempuan dan penurunan kekuatan otot terjadi selama proses penuaan.Dalam permainannya, tangan merupakan organ vital yang sangat penting untuk mendukung terciptanya performa yang baik. Agar faktor kekuatan otot peras tangan dapat berkembang optimal, seorang pemain bulutangkis perlu latihan rutin dengan memperhatikan pola latihan.

\section{B. Metode}

Metode penelitian ini menggunakan pendekatan penelitian kualitatif. Dengan jenis penelitian ini adalah penelitian analisis deskriptif. Suharsimi Arikunto (2002: 302) menyatakan bahwa "penelitian deskriptif tidak dimaksudkan untuk menguji hipotesis tertentu, tetapi hanya menggambarkan "apa adanya" tentang sesuatu variabel, gejala atau keadaan". Karena masih di era pandemi covid-19, maka alasan peneliti mengambil 
pendekatan penelitian kualitatif dengan metode dekriptif adalah karena terbatasnya tempat pengambilan data karena terjadinya pembatasan sosial bersekala besar (PSBB), maka dari itu penelitian ini bertujuan melihat suatu apa adanya. Pendekatan penelitian ini adalah mengumpulkan data yang berupa angka, sehingga penelitian ini disebut penelitian analisis deskriptif. Metode yang digunakan adalah survei. Menurut Suharsimi Arikunto (2006: 312), metode survei merupakan penelitian yang biasa dilakukan dengan subjek yang banyak, dimaksudkan untuk mengumpulkan pendapat atau informasi mengenai status gejala pada waktu penelitian berlangsung. Penelitian ini untuk menggambarkan mengenai kekuatan otot peras tangan anggota unit kegiatan mahasiswa (UKM) Universitas PGRI Adi Buana Surabaya.

Data penelitian yang harus di kumpulkan yaitu bersumber dari data pimer dan sekunder, yang di maksud dengan sumber data dalam penelitian ini adalah subjek dari mana data tersebut di peroleh, dalam penelitian ini peneliti menggunakan dua sumber data. Sumber Data Primer dalam penelitian ini yaitu anggota unit kegiatan mahasiswa (UKM) Universitas PGRI Adi Buana Surabaya. Sumber data sekunder dapat di peroleh dari anggota UKM dengan kreteria data yaitu: (1) daftar hadir minimal 75\% (keaktifan mengikuti latihan), (2) pemain merupakan anggota UKM Bulutangkis Universitas PGRI Adi Buana Surabaya. Berdasarkan kriteria tersebut yang memenuhi berjumlah 20 pemain. Metode pengumpulan data yang digunakan pada penelitian ini menggunakan metode tes. Karena data yang dicari merupakan tingkat kemampuan individu setiap anggota UKM yang menjadi objek penelitian. Tes yang dilakukan pada penelitian ini untuk mengukur kekuatan statis otot-otot peras tangan yang digunakan untuk melakukan pukulan dalam olahraga bulutangkis. Semakin besar kekuatan otot lengan yang dihasilkan maka akan menghasilkan fungsinya dengan optimal. Cara melakukan tes dengan menggunakan alat ukur yang bernama hand dynamometer grip. Teknik Analisis Data merupakan kumpulan data yang diperoleh dari tes dan pengumpulan data. Untuk data yang diperoleh harus sesuai dengan imliah, reliabel, akurat, tepat, relevan, dan sesuai dengan tujuan penelitian. Analisis yang digunakan dalam penelitian ini adalah analisis deskriptif. Menurut Sugiyono (2018: 207), statistik deskriptif merupakan statistic yang digunakan untuk menganalisis data dengan cara mendiskripsikan atau menggambarkan data yang telah terkumpul sebagaimana adanya tanpa bermaksud membuat kesimpulan yang berlaku untuk umum atau generalisasi. Pada penelitian analisis deskriptif ini dibantu dengan progam SPSS 20.

\section{Hasil dan Pembahasan}

Hasil penelitian ini adalah analisis deskriptif. Deskripsi data yang akan di sajikan adalah data hasil pengukuran kekuatan otot peras tangan kanan dengan Menggunakan tes Grip Strength Tes yang dilakukan anggota unit kegiatan mahasiswa (UKM) Universitas PGRI Adibuana Surabaya sebanyak 20 pemain. Dalam penelitian ini yaitu anggota unit kegiatan mahasiswa (UKM) Universitas PGRI Adibuana Surabaya, kemudian anggota unit kegiatan mahasiswa (UKM) Universitas PGRI Adibuana Surabaya tersebut melakukan Grip Strength Tes untuk mengetahui seberapa besar kekuatan otot peras tangan. Hasil analisis data yaitu anggota laki-laki dan perempuan melakukan Grip Strength Tes kemudian peneliti dapat memperoleh deskripsi data rata-rata, standart deviasi (SD), varian, nilai maksimal, nilai minimal. Analisis data digunakan untuk menjawab hipotesis yang diajukan. Sebelum analisis data dilakukan, maka perlu dilakukan uji pesyaratan analisis yaitu dengan Analisis Deskriptif. Hasil analisis deskriptif dapat dilihat sebagai berikut. Deskripsi data hasil penelitian ini dimaksudkan untuk menggambarkan data- data dalam bentuk ringkasan tentang kekuatan otot peras tangan anggota unit kegiatan mahasiswa (UKM) Universitas PGRI Adibuana Surabaya. 
Creating Productive and Upcoming Sport Education Profesional Hmzanwadi University

Vol.4, No.1, Juni 2021, Hal. 32-38

e-ISSN 2614-8781

Tabel 1 Kekuatan Otot peras tangan Anggota Laki-Laki

\begin{tabular}{cccccc} 
& Frequency & Percent & $\begin{array}{l}\text { Valid } \\
\text { Percent }\end{array}$ & $\begin{array}{l}\text { Cumulative } \\
\text { Percent }\end{array}$ \\
\hline Valid & $>55,50=$ baik sekali & 1 & 10,0 & 10,0 & 10,0 \\
& $46,50-55,0=$ baik & 5 & 50,0 & 50,0 & 60,0 \\
& $36,50-46,00=$ sedang & 1 & 10,0 & 10,0 & 70,0 \\
& $27,50-36,00=$ kurang & 2 & 20,0 & 20,0 & 90,0 \\
& $<27,00=$ kurang sekali & 1 & 10,0 & 10,0 & 100,0 \\
\hline Total & 10 & 100,0 & 100,0 &
\end{tabular}

Berdasarkan output "Distribusi Frekuensi" pada anggota laki-laki unit kegiatan mahasiswa (UKM) Bulutangkis Universitas PGRI Adibuana Surabaya, diketahui nilai N valid adalah 10, artinya jumlah responden yang dimasukan ke SPSS adalah 10 anggota (UKM). Kemudian output "anggota laki-laki" bagian frequency dan percent diketahui ada 1 atau $10 \%$ anggota yang mendapatkan nilai $>55,50 \mathrm{~kg}$ selanjutnya ada 5 atau $50 \%$ anggota mendapatkan nilai 46,50-55,00 kg selanjutnya ada 1 atau $10 \%$ anggota mendapatkan nilai $36,50-46,00 \mathrm{~kg}$ selanjutnya ada 2 atau $20 \%$ anggota yang mendapatkan nilai 27,50-36,00 kg yang terakhir ada 1 atau $10 \%$ anggota mendapatkan nilai $<27,00 \mathrm{~kg}$

Tabel 2 Kekuatan Otot Peras Tangan Anggota Perempuan

\begin{tabular}{llcccc} 
& Frequency & Percent & $\begin{array}{l}\text { Valid } \\
\text { Percent }\end{array}$ & $\begin{array}{c}\text { Cumulative } \\
\text { Percent }\end{array}$ \\
\hline Valid & $32,50-41,00=$ baik & 3 & 30,0 & 30,0 & 30,0 \\
& $24,50-32,0=$ sedang & 4 & 40,0 & 40,0 & 70,0 \\
& $18,50-24,00=$ kurang & 2 & 20,0 & 20,0 & 90,0 \\
& $<18,00=$ kurang sekali & 1 & 10,0 & 10,0 & 100,0 \\
\hline & Total & 10 & 100,0 & 100,0 &
\end{tabular}

Berdasarkan output "Distribusi Frekuensi" pada anggota Perempuan unit kegiatan mahasiswa (UKM) Bulutangkis Universitas PGRI Adibuana Surabaya, diketahui nilai N valid adalah 10, artinya jumlah responden yang dimasukan ke SPSS adalah 10 anggota (UKM). Kemudian output "anggota perempuan" bagian frequency dan percent diketahui ada 3 atau 30\% anggota yang mendapatkan nilai 32,50-41,00 kg selanjutnya ada 4 atau $40 \%$ anggota mendapatkan nilai 24,50-32,00 kg selanjutnya ada 2 atau $20 \%$ anggota mendapatkan nilai $18,50-24,00 \mathrm{~kg}$ yang terakhir ada 1 atau $10 \%$ anggota mendapatkan nilai $<18,00 \mathrm{~kg}$.

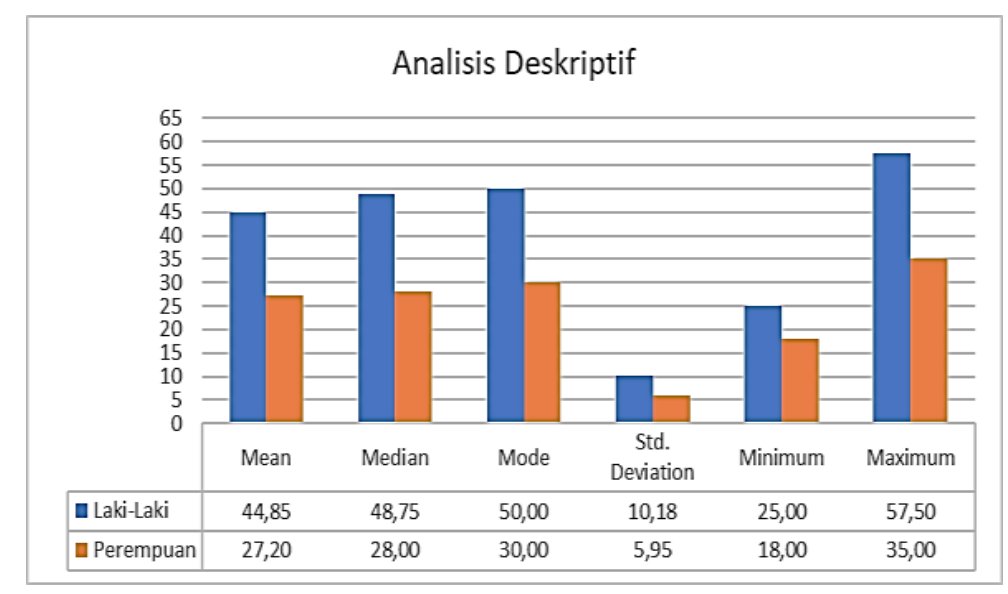

Gambar 1. Diagram Batang Hasil Analisis Deskriptif Kekuatan Peras Otot Tangan 
Hasil analisis deskriptif penelitian tentang kekuatan otot peras tangan pada anggota laki-laki dan perempuan unit kegiatan mahasiswa (UKM) Universitas PGRI Adibuana Surabaya. Untuk skor terendah pada anggota laki-laki (minimum) 25,00 dan untuk skor terendah anggota perempuan (minumum) 18.00. Kemudian untuk skor tertinggi anggota laki-laki (maksimum) 57,50, dan untuk skor tertinggi anggota perempuan (maksimum) 35,00 rata- rata anggota laki-laki (mean) 44,85 dan nilai rata-rata anggota perempuan (mean) 27,20. kemudian untuk nilai tengah anggota laki- laki (median) 48,75, dan nilai tengah anggota perempuan (median) 28,00. Nilai yang sering muncul pada anggota laki-laki (mode) 50,00, dan nilai yang sering muncul pada anggota perempuan (mode) 30,00. Standar deviasi anggota laki-laki (SD) 10,18 dan Standar deviasi anggota perempuan (SD) 5,95. Mengukur kekuatan otot peras tangan kanan menggunakan alat Hand Dynamometer. Grip Strength Tes. dilakukan untuk mengetahui kemampuan dari otot atau sekelompok otot untuk mengatasi tahanan atau beban dalam menjalankan aktivitas olahraga bulutangkis. Untuk dapat kekuatan otot peras tangan, agar kekuatan otot peras tangan bertambah maka pemain perlu untuk melakukan latihan dengan program latihan yang berkualitas untuk menunjang penguasaan teknik pukulan dengan baik. Kekuatan dapat dikatakan merupakan aktifitas gerakan manusia.

Dari hasil penelitian diatas menunjukan bahwa rata-rata kekuatan otot peras tangan pada anggota laki-laki adalah 44,85. Maka kekuatan otot peras tangan untuk anggota lakilaki unit kegiatan mahasiswa (UKM) Universitas PGRI Adi Buana Surabaya. Untuk kekuatan otot peras tangan kanan termasuk dalam kategori "sedang". Kemudian untuk kekuatan otot peras tangan pada anggota perempuan rata-rata adalah 27,20. Maka kekuatan otot peras tangan untuk anggota perempuan unit kegiatan mahasiswa (UKM) Universitas PGRI Adi Buana Surabaya. Untuk kekuatan otot peras tangan kanan termasuk dalam kategori "sedang". Dari hasil pembahasan diatas dapat diketahui bahwa keseluruhan kekuatan otot peras tangan pada anggota unit kegiatan mahasiswa (UKM) bulutangkis Universitas PGRI Adi Buana Surabaya termasuk dalam kategori "Sedang”.

\section{Simpulan}

Berdasarkan data yang dikumpulkan, dari hasil pengolahan data dan analisis data, maka dapat ditarik simpulan bahwa kekuatan otot peras tangan digunakan untuk melakukan pukulan agar dapat menghasilkan ketepatan, kekuatan pukulan, dan akurasi yang sempurna. kekuatan otot peras tangan pada anggota unit kegiatan mahasiswa (UKM) bulutangkis Universitas PGRI Adi Buana Surabaya. Hasil untuk anggota laki-laki berdasarkan nilai ratarata, yaitu 44,85. Kemudian untuk anggota perempuan berdasarkan nilai rata-rata, yaitu 27,20. Dapat diambil kesimpulan bahwa, tingkat keseluruhan kekuatan otot peras tangan pada anggota unit kegiatan mahasiswa (UKM) bulutangkis Universitas PGRI Adi Buana Surabaya berada dalam kategori "Sedang". Jadi untuk kekutan otot peras tangan pada angota unit kegiatan mahasiswa (UKM) bulutangkis Universitas PGRI Adi Buana Surabaya perlu mengembangkan lagi latihan terutama pada kekuatan otot peras tangan yang berguna untuk menunjang penguasaan teknik pukulan dengan baik.

\section{Daftar Pustaka}

Arikunto, S. (2010). Metode peneltian. Jakarta: Rineka Cipta.

Arikunto, S. (2021). Dasar-dasar Evaluasi Pendidikan Edisi 3. bumi aksara.

Arifin, Z. (2020). Metodologi penelitian pendidikan. Jurnal Al-Hikmah, 1 (1). 
Aditama, P. R. Ajzen, I. 2005. Attitudes, Personality and Behavior Second Edition. New York: Open University Press. Neuman, W. Lawrence. 2013. Metodologi Penelitian Sosial: Pendekatan Kualitatif dan Kualitatif Edisi \&. Jakarta. PT. Indeks Jakarta. Sugiyono. Prof, Dr.(2012). Metode Penelitian Kuantitatif, Kualitatif, Dan R\&D.

Baskoro, D. A. (2016). Hubungan kekuatan otot lengan, VO2 max dan persepsi kinestetik terhadap akurasi tembakan jarak 50 meter. ACTIVE: Journal of Physical Education, Sport, Health and Recreation, 5 (3), 130-133.

Hassan, N., Noor, F., Ahmad, S., \& Fazili, KM (2016). Usia fusi epifisis radial distal dan ulnar dari radiografi tangan-Sebuah studi pada populasi Kashmir. Sains \& Keadilan , 56 (6), 431-436.

Intani, A. D. (2020). Upaya Meningkatkan Hasil Servis Pendek Dalam Permainan Bulu Tangkis Melalui Gaya Mengajar Problem Sovling Pada Siswa Kelas X Di Sma Negeri 1 Simpang Empat. Focus Pjkr Upmi, 1 (1), 41-49.

Jati, B. M., \& Sudarsono, S. (2021). Perbedaan Pengaruh Latihan Plyometric Dan Latihan Circuit Terhadap Jumping Smash Pada Atlet Bulutangkis $\mathrm{Pb}$ Independent Karanganyar Tahun 2020. Jurnal Ilmiah Spirit, 21 (1), 96-107.

Maskum Ali. (2009). metode penelitian dalam olahraga. Surabaya: Falkulitas Ilmu Keolahragaan Universitas Negeri Surabaya.

Putro, B. R. H. (2016). Perbedaan Hasil Latihan Shadow Menggunakan Isyarat Lampu dan Aba-Aba Pelatih Terhadap Agility Footwork Atlet Bulutangkis PB Sehat Semarang (Doctoral dissertation, Universitas Negeri Semarang).

Sugiyono, F. X. (2017). Neraca pembayaran: Konsep, Metodologi dan penerapan (Vol. 4). Pusat Pendidikan Dan Studi Kebanksentralan (PPSK) Bank Indonesia.

Suharsimi. (2006). Prosedur Penelitian; Suatu Pendekatan Praktek. Yogyakarta: Rineka Cipta.Kisner, C., \& Colby, L. (2012). Therapeutic Exercise Foundations and Techinques Fifth Edition. Philadelphia: F.A. Davis Company.

Soenardi, A., Fiqri, A., Trisnarizki, L., Kariosentono, H., Probandari, AN, Mawardi, P., ... \& Ellistasari, EY (2020). Prevalensi Kutil Kelamin dan Faktor Risiko Terkait pada Populasi LSL di Surakarta, Indonesia. Jurnal Penelitian Medis dan Biologi Malaysia , 7 (1), 7-12.

Sugiyono. (2018). Metode Penelitian Kuantitatif, Kualitatif, dan R\&D. Bandung: Alfabeta.

Suharno H.P. (1986). Ilmu Kepelatihan Olahraga. Yogyakarta: FPOK-IKIP Yogyakarta.

Syahri Alhusin. (2007). Gemar Bermain Bulutangkis. Surakarta: Direktorat Jendral Pendidikan Dasar dan Menengah.

Sudarsono, S. (2011). Penyusunan program pelatihan berbeban untuk meningkatkan kekuatan. Jurnal Ilmiah SPIRIT, 11(3).

Sajoto, M. (2009). Program Olahraga Nonprestasi untuk meningkatkan Sumber Daya Mahasiswa. Ilmu Pendidikan: Jurnal Kajian Teori dan Praktik Kependidikan , 27 (1).

Suharsimi, A. (2006). metodelogi Penelitian. Yogyakarta: Bina Aksara.

Tim Kkn Bmc Unnes 2020. (2020). Buku Saku Covid-19 Universitas Negeri Semarang. Https://Doi.Org/10.1016/J.Ccl.2011.03.0 02 